of gastro-enteritis which are never investigated. When food poisoning occurs, the usual history is that sereral people are attacked nearly simultaneously by serere sickness; they compare notes and decide that a certain article of food or drink or a certain dish must have been the cause. Generally speaking the suspicion is found on incuiry to be justified, and, when specimens are available for bactcriological examination, it is usually possible to complete the proof by isolating one of the salmonella types both from the suspected food and from the sufferers. But not uncommonly acute gastro-enteritis attacks a single individual in a household, and suspicion is not directed to food or drink as the cause, more especially as it often happens that meals have all been in common and the commensals escape illness. Such cases may evade investigation entirely. Occasionally, howerer, the person so attacked may die after an illness lasting from one to fifteen days, and may become the subject of a coroner's inquest and a pathological examination. The result may be that a salmonella is found in the alimentary canal and throughout the organs, exactly as in the fatal cases in a larger food-poisoning outbreak. The source of infection in these solitary fatal cases almost always remains undiscovered; the sufferer may be too ill to be questioned, or suspicion may not eren arise till after the fatal ending and the bacteriological report. What I should like to snggest js that the cause of some of these solitary cases is an infected egg. Obriously the solitary nature of the infection, no one else suffering in the family or among those sharing the same meals, indicates an unshared dish as the rehicle: an egg is one of the commonest and most ronspicuously unshared of such unshared dishes in ordinary life, and in spite of its notorious innocence should not escape suspicion.

$$
\begin{aligned}
& \text { ReFERENCE. } \\
& 1 \text { Journ. Infect. Dik., vol. } 26, \text { p. } 217
\end{aligned}
$$

\section{THE TREATMENT OF VARICOSE VEINS BY INJECTION.}

\author{
BY
}

NOEI, SCOTT, M.R.C.S., I.R.C.P.,

SURGICAL ASSISTANT, OIT-PATIENT DEPARTMENT, ROYAL WATERLOO HOSPITAL.

THe treatment of varicose veins by injection originated over seventr-five years ago, but, although Professor Sicard of Paris treated a large number of patients by this method from 1915 onwards, it was not generally recognized in Great Britain until a few years ago. It was introduced at the Waterloo Hospital in 1925 by $\mathrm{Mr}$. Rodney Maingot as a rontine treatment; in that year the Varicose Vein Clinic was inangurated, and the number of cases has steadily increased until we are now dealing with some thousands a. ycar.

We use an ordinary 5 c.cm. Record syringe with a No. 16 needle. As we treat a large number of patients in each chinic it is impossible to sterilize the syringe and meedle by boiling. After each injection the syringes and needles are washed out with distilled water and are placed in spirit: thes are then rearly for the next patient.

The ideal position of the pationt is prone upon a couch; the veins are collapsed and therefore more easily injected. This is only possible, however, when the veins are large and remain very apparent even when the patient is lving down. In most cases the patient is treated while sitting on an ordinary chair. But in a certain numiber of cases neither of these courses is practicable, and it is then necessary for the patient to stand on a low stool with the weight of the body on the affected limb.

The skin over the vein to be injected is sterilized with spirit. It is not desirable to use a tourniquet because it produces venous engorgement, it is difficult to manage single-handed, and it causes considerable pain to the patient.

Three solutions are in general use at present-namely, (1) quinine wetlane (quinine hihydrochloride 4 grams, urethane 2 grams, and distilled water to $30 \quad r . c m$.$) ;$ (2) lithium salicylate 30 per cent. with tutocaine 0.75 per cent.; and (3) odium chloride 20 per cent. with tutocaine
0.75 per cent. The one in most use, as far as we are concerned, is the lithium preparation; it scleroses well, and produces no symptoms. The only practical objection to its use is that it does not keep well; as a rule after about ten clays it starts to turin brown from cxposure to light and heat, and has to be thrown away. The sodiun chloride preparation is very good for the injection of small veins, especially if they are thin-walled and the skin over them is atrophic; in these cases it is impossible to inject the other solutions, which will not be tolerated. It should, however, never be used in large healthy veins. From the point of view of thrombosis quinine urethane is the best preparation, but many patients cannot tolerate it, even in the smallest doses. Any dose over 2 e.cm. is always liable to give rise to buzzing in the ears, flushes, headaches, and hypogastric pains; these occur almost inmediately after injection, and may even lead to loss of consciousness. Although the patient recovers quickly and the symptoms rapidly disappear they give rise to a certain amount of apprehension as to future treatment, and are also very undesirable when there are other patients in the room. For this reason we have abandoned the use of quinine urethane except in cases of the "twin injection," with which I shall deal later on.

The dosage is important. The usual dose of lithium and sodium chloride is $4 \mathrm{c.cm}$. and of quinine urethane 2 c.cm. It is never advisable to give more than $2 \mathrm{c.cm}$. of quinine at one sitting, and at first 1 c.cm. of any solution is the most that should ever be injected. It is important to see how the patient reacts; by starting with small doses, and thereby minimizing the pain, (ontedence is won, and larger doses can be reached without any untoward effect. Injection of the full dose of $4 \mathrm{c.cm}$. at the first sitting might produce pain and cramp, and, in a certain number of cases, cause the patient to cease attending for further treatment.

In injecting the solution into the vein it is advisable as a rule to work from below upwards. The skin is sterilized, the selected vein is steadied by the left hand, and the needle is then inserted obliquely from below upwards in the line of the vein. When it is felt that the rein has been entered, the plunger of the srringe is cautiously pulled out, and, if the needle is in the vein, bloed will flow easily into the syringe. Injection cas then be performed. If the operator is uncertain whether the needle is in the vein he should repeat the procedure of pulling out the plunger. If air bubbles appear it is a sign that the needle has gone through the vein or that its point lies in the subcutaneous tissues. He must then either alter the position of his needle until he has successfully secured re-cntry, or, in any case of cloubt, withdraw it and try again. It is always advisable to inject in one spot, if possible, and small doses in multiple punctures should be avoided. During injection the point of the needle must be held perfectly steady, since tho slightest deviation will probably cause complete penetration of the vein and the subsequent discharge of the solution into the surrounding tissues. The solution should be injected slowly and steadily. When the injection has been completed a pad of wool should be held over the site during withdrawal of the needle to prevent the leakage of blood. The limb is then raised, the site of injection is wiped dry with spirit on a small piece of cotton-wool, and cither ordinary plaster or "elastoplast" is fixed to the spot. There is no neeessity for the patient to lie up after the injection. There may be a certain amount of pain or cramp persisting for a fer minutes, but as a general rule patients can walk away immediately after the treatment.

Immediate Local Effects.-These are as follows: (1) the vein may collapse or dilate after injection; (2) the vein may become hard at once; (3) there may be severe pain at the time of injection; (4) there may be external haemorrhage and/or subcutaneous bruising; (5) there may be no change; (6) thrombosis may occur and a satisfactory result ensie. Thrombosis usually takes place in froin six to twenty-four hours.

Immediate General Effects.-Shock may occur, also collapse and fainting. In cases of quinine injection there may be buzzing of the ears, headache, etc. 
Late Lacal Effects.-These consist principally of ecchymoses and gangrene of the vein, and ulcer; of these, the most common by far is the "injection ulcer," which is due in most eases to the deposition of the solution in the tissues round the vein. It is serious and painful, and four to six months elapse before a cure is effected. No case of injection vileer should ever oceur; it is in al cases due to carelessmess in the administration of the injection. In most cases the operator has entered the vein successfully, but in the course of injeetion, through a momentary unsteadiness or movement of the patient, the vein has been penetrated and the solution deposited in the surrounding tissues. This should never happen if the precaution of withdrawing the plunger of the syringe in moments of doubt has been observed. The last late loral effect is the complete thrombosis and gratual elimination of the vein. This takes some three to twelve months to occur, the vein gradually becoming hard and cord-like to the touch. Over the bony surfaces the process is slow, but in the thigh it is mueh quieker, and as a general rule it may be stated that the rein should be practically obliterated in twelve months' time.

There is only one important late general effect-pulmonary enbolism. This is a very rare occurrence; in some ten thousand cases treated at the Waterloo Hospital there has so far been no record of such a sequel. Yet there is a chance that this may oecur, since there are records in the medical literature of many cases.

In those cases which $I$ have indicated above where no change takes place after injection there is one infallible method" of treatment, which is known as the "twin injection." It is generally necessary to make use of this when the veins are rery large with extensive varicosity. The selected rein receives simultaneous injections of $4 \mathrm{c} . \mathrm{cm}$. of lithium and $2 \mathrm{c.cm}$. of quinine urethane solution, the sites of injection being 3 to 5 inches apart. It is possible to do this single-handed by injecting the lithium first and the quinins immediately afterwards, but in actual practice it is much more satisfactory to have assistance for one of the in jections. The quinine must never be injected first because, if this is done, when the lithium is being injected and the barrel of the syringe is being pulled out, there is a great Fikelihood of withdrawing some of the quinine from the vein, and this immediately causes clotting in the syringe. This "twin injection" invariably causes clotting, but it must be emphasized again that it should not be employed unless the veins are very large.

Other solutions have been tried by us, but have been abandoned for various reasons. Pure carbolic (98 per cent.) is a sticky solution; it spoils the syringe, the dose of 1-3 m is difficult to assess owing to the stickiness, and it causes perivenitis, and, occasionally, haematuria. Alcohol (50-100 per cent.) in a dose of 1-5 m is too painful. Sodium citrate (20-50 per cent.) has been given in doses of 0.5 to 4 c.cm., but the results proved unreliable. Sodium salicylate (20-50 per cent.) in a dose of $1-4 \mathrm{~m}$ was also imreliable; about 60 per cent. of results are good if this solution is used exctusirely.

In a number of hospital cases there is severe varicose vein ulceration. If the ulcer is very Iarge the limb should always be $x$-rayed in order to deternine whether or not there is any periostitis. Should the bone be inrolved the ulcer will naturally take longer to heal under treatment. In all cases a Wassermann test should be performed.

\section{Treatment of Varicose Ulcer.}

If no veins are visible Unna's paste bandlage should be applied once a week. Where veins are present they should be injected weekly in addition to the use of the bandage. In severe cases the base of the ulcer should be injected with quinine urethane. Two sites are selected, and into each $2-5 \mathrm{~m}$ of quinine is injected at an oblique angle, the one from above the other from below. In this way a small " istand" of the ulcer is cut off and heals; our method is to attack and heal a series of "islands" until the entire surface of the ulcer is healed. In very small ulcers $2 \frac{1}{2}$ per cent. tamnic acid solntion on lint is applied to the part every four hours. This forms a crust over the surface of the vilcer and stimulates healing under the crust.
The treatment of an "injection ulcer" is as follows. For the first few days hot fomentations are applied. They are followed by pure hydrogen peroxide, and then by the application of calamine Iotion. These ulcers are very painful, and the patient should be warned that a cure will not occur in less than three to six months.

The contraindications to treatment are five in number. (1) Pregnancy; the veins will probably disappear after confinement, and treatment should never be given during pregnancy. (2) Deep thrombosis. (3) Acute septic thrombo-phlebitis; at least three months must be allowed to elapse from the time that all inffammation has disappeared before treatment is attempted. (4) Adranced heart, lung, or kidney disease; diabetes; and high blood pressure. (5) If the varicose vein ulcer is very septic it is advisable to clean it up first before injection treatment is attempted.

We have found from experience that the following rules are highly important, if a satisfactory result is to be obtained in the treatment of varicose veins by this method.

Rulcs for Injection.

1. Never inject more than 1 c.cm. at the first sitiling.

2. Never inject more than 6 c.cm. at the one sitting in one

3. Never inject more than $2 \mathrm{c.cm}$. of quinine urethane at the one sitting.

4. Never inject more than 4 c.crr. of lithium or sodium chloride.

5. Inject weekly.

6. Avoid small doses and multiple punctures.

7. Work from below upwards.

8. Never inject if the veins aro painful, or in $-t$ the time of
the introduction of the solution there is bukging the introduction of the solution there is buking of the veins.

\section{Remarks.}

An injection ulcer appears in about 1 per cent. of all cases. With quinine or lithium about 20 per cent. of cases will not "take." These 20 per cent. of cases will "take" with the twin injection. For a few days following the injection the limb may be painful, and patients should be warned of this; they should also be warned of the local and general effects. When injection is performed near the ankle some oedema of the feet nearly always results. The final results may be very good, but varicose veins may form in other parts of the limb, and even veins which have thrombosed as a result of tho treatment may recanalize.

Provided that there are no complications or contraindications there are no cases which will not, with cave and time and judgement, respond satisfactorily to treatment by the injection of suitable sclerosing solutions.

\section{INTRAVENOUS SCLEROSING SOLUTIONS.}

\section{T. HENRY TREVES BARBER, M.D., B.Sc.}

Ir has frequently been stated that the nature of the clot, subsequent to sclerosing injections, is dependent upon the chemical used for the injection, some forming a soft friable clat, others a firm adherent one. As a matter of fact the consistency of the clot is entirely independent of the drug injected.

To elucidate this important question the following experiments have been made. They prove that: (1) the injected solution has but a very fugitive effeet upon the endothelium of the injected vein; (2) no primary formation of a clot is possible from the blood itself with the solutions and doses used, since the normal clotting of the blood (in vitro) is retarded by its admixture with them.

Withdraw from a varicose vein 2 or $3 \mathrm{c.cm}$. of blood, and pour into a test tube, $\mathbf{A}$; it is dark red. Leave the needle in place, adjust it to a syringe charged with $5 \mathrm{c.cm}$. of a 20 per cent. solution of $\mathrm{NaCl}$ and inject. When the injection is about half-way done, aspirate some of the blood inte the syringe; it will be seen to be of a brighter colour. At the end of the injection the piston is immediately and slowly withdrawn. Brilliant scarlet blood flows into the syringe for fourteen to forty-five seconds, according to the rate of the circulation in the selected vein (rapid change of colour is found in those vessels having a sufficient circulation). In all cases, however, within a full minute of terminating the injection the
blood appears to have resumed its normal colour. 